\title{
Strength in diversity: methods and analytics
}

\author{
Maria Petrescu $^{1,2} \cdot$ Anjala S. Krishen ${ }^{3}$
}

Published online: 5 November 2019

(c) Springer Nature Limited 2019

Diversity refers to the existence of differences within a group. Tolerance represents the level of ability to recognize and respect other people's values and beliefs and it means recognizing that diversity is a strength. In the current data environment, tolerance towards a diversity of methodologies and methods is becoming key to understating, explaining, and predicting marketing phenomena. For example, the global datasphere will grow from 33 zettabytes in 2018 to 175 by 2025 ; about $30 \%$ of the world's data will need realtime processing and nearly $80 \%$ of it will be unstructured (Reinsel et al. 2018). Given this growth, organizations that are capable to using a diversity of methodologies to analyze their data will experience a competitive advantage. Marketers need to be equipped to extract underlying insights from their data; those insights can enable them to measure, track, understand, and interpret the marketplace (Berger et al. 2019). As previous research indicates, no one theory, or set of theories that justifies the use of a particular method can be comprehensive (Midgley et al. 2017), especially when dealing with such a large quantity of unstructured data.

\section{Triangulation versus pluralism}

Most recent methodologies can be perceived as isolationist, prescribing only 'one best way' of doing things, while, at the same time, encouraging a narrow range of methods (Midgley et al. 2017). For example, triangulation can provide a more in-depth understanding of the phenomenon in question, as it combines the rigor and validation of quantitative statistical

Maria Petrescu

maria.petrescu@icn-artem.com

Anjala S. Krishen

Anjala.krishen@unlv.edu

1 ICN Business School Artem, CEREFIGE Laboratoire, Nancy, France

2 Colorado State University Global, Aurora, CO, USA

3 Lee Business School, University of Nevada, Las Vegas, USA methods with the exploratory power of qualitative and indepth inquiry. In studies such as these, qualitative methods are usually assigned during the exploratory phase (Branthwaite and Patterson 2011; Denzin and Lincoln 2005). Most articles employing mixed methods have a positivist orientation (Bahl and Milne 2010) and triangulated research is limited in marketing, despite its theoretical potential (Hanson and Grimmer 2007; Hunt 1994; Petrescu and Lauer 2017).

However, even the use of triangulation in marketing research is relatively limited compared to the potential of using a pluralist system of purposes, including explanation and prediction, that can be pursued through a diversity of methods (Midgley et al. 2017). For example, in practice, marketing analysts are often more likely to employ a diverse system of methods and integrating them within the same marketing analytics and data analysis platform, to gain marketing intelligence and make predictions. Nevertheless, both marketing research academics and practitioners need to develop a pluralist view on diversifying and innovating methodologies to integrate solutions using sophisticated analytical tools.

\section{Strength in diversity}

Recent research in marketing and related fields indicates that scholars are realizing the need to become methodologically adaptive. Some new examples include: (1) Mikalef et al. (2019) employ fuzzy-set qualitative analysis (a pseudo-qualitative approach) with survey data to study big data analytics and firm performance, (2) Arifine et al. (2019), Krishen et al. (2014), and Krishen et al. (2019) provide sequential, mixed-method designs with primary qualitative studies followed by secondary quantitative models, and (3) Warren et al. (2019) conduct a series of in-depth interviews, focus groups and other qualitative methods followed by several experiments to conceptualize a new construct called brand coolness. Concerning marketing analytics, there is a need not only for more tolerance regarding a diversity of methodologies and methods employed in research and practice but 
also a necessity to embrace a pluralism of views and skills (Salo 2017). For these reasons, we need more marketing analytics-related research focused on:

- The viability of methodologies derived from various business, social science, and quantitative disciplines for the extraction of marketing analytics and intelligence;

- The use of all types of qualitative and quantitative methodologies in analyzing unstructured data for descriptive, explanatory, and especially predictive purposes;

- Different methods of transforming qualitative unstructured data into quantitative variables for modeling and predictive purposes;

- The integration of all types of qualitative and quantitative methodologies and software platforms for the creation of intelligence dashboards.

Methodological tolerance means understanding that diversity is a strength that can help extract better insights from data, enhance its power of prediction, and increase the methodological knowledge and overall intelligence of marketing research. Ultimately, by increasing methodological diversity, marketing academics as well as practitioners can improve collaboration and knowledge cross-fertilization with other disciplines.

\section{References}

Arifine, G., R. Felix, and O. Furrer. 2019. Multi-brand loyalty in consumer markets: A qualitatively-driven mixed methods approach. European Journal of Marketing 53 (11): 2419-2450. https://doi. org/10.1108/ejm-07-2017-0474.

Bahl, Shalini, and George R. Milne. 2010. Talking to ourselves: A dialogical exploration of consumption experiences. Journal of Consumer Research 37 (June): 176-196.

Berger, J., A. Humphreys, S. Ludwig, W.W. Moe, O. Netzer, and D.A. Schweidel. 2019. Uniting the tribes: Using text for marketing insight. Journal of Marketing. https://doi.org/10.1177/00222 42919873106.

Branthwaite, Alan. 2011. The power of qualitative research in the era of social media. Qualitative Market Research: An International Journal 14 (4): 430-440.

Denzin, Norman K., and Yvonna S. Lincoln. 2005. The SAGE handbook of qualitative research. Thousand Oaks: SAGE.

Hanson, Dallas, and Martin Grimmer. 2007. The mix of qualitative and quantitative research in major marketing journals. European Journal of Marketing 41 (1/2): 58-70.

Hunt, Shelby D. 1994. Our rethinking marketing: Our discipline, our practice, our methods. European Journal of Marketing 28 (3): $13-25$.
Krishen, A.S., O. Berezan, and C. Raab. 2019. Feelings and functionality in social networking communities: A regulatory focus perspective. Psychology \& Marketing 36 (7): 675-686. https:// doi.org/10.1002/mar.21204.

Krishen, A.S., R. Raschke, P. Kachroo, M. LaTour, and P. Verma. 2014. Promote me or protect us? The framing of policy for collective good. European Journal of Marketing 48 (3/4): 742-760.

Midgley, G., J. Nicholson, and R. Brennan. 2017. Dealing with challenges to methodological pluralism: The paradigm problem, psychological resistance and cultural barriers. Industrial Marketing Management 62: 150-159.

Mikalef, P., M. Boura, G. Lekakos, and J. Krogstie. 2019. Big data analytics and firm performance: Findings from a mixed-method approach. Journal of Business Research 98: 261-276. https://doi. org/10.1016/j.jbusres.2019.01.044.

Petrescu, M., and B. Lauer. 2017. Qualitative marketing research: The state of journal publications. The Qualitative Report 22 (9): 2248-2287.

Reinsel, David, John Gantz, and John Rydning. 2018. The digitization of the world from edge to core. An IDC White Paper, \#US44413318 https://www.seagate.com/files/www-content/ourstory/trends/files/idc-seagate-dataage-whitepaper.pdf.

Salo, J. 2017. Social media research in the industrial marketing field: Review of literature and future research directions. Industrial Marketing Management 66: 115-129. https://doi.org/10.1016/j. indmarman.2017.07.013.

Warren, C., R. Batra, S.M.C. Loureiro, and R.P. Bagozzi. 2019. Brand coolness. Journal of Marketing 83 (5): 36-56. https://doi. org/10.1177/0022242919857698.

Publisher's Note Springer Nature remains neutral with regard to jurisdictional claims in published maps and institutional affiliations.

Maria Petrescu is an Associate Professor of Marketing at ICN Business School Artem, Nancy, France. Her main research areas include marketing analytics and digital marketing. Dr. Petrescu has published articles in journals such as Psychology \& Marketing, the Journal of Marketing Management, Public Management Review, Journal of Product and Brand Management, the Journal of Retailing and Consumer Services, and the Journal of Internet Commerce.

Anjala S. Krishen is a Professor of Marketing and International Business and Special Advisor to the Dean for Research at University of Nevada, Las Vegas, has a B.S. in Electrical Engineering from Rice University, and an M.S. Marketing, MBA, and Ph.D. from Virginia Tech. Krishen held management positions for 13-years before pursuing a doctorate. As of 2019, she has published over 50 peer-reviewed journal papers in journals including Journal of Business Research, Psychology \& Marketing, Information \& Management, European Journal of Marketing, Journal of Travel \& Tourism Marketing, and Journal of Marketing Education. In 2016, she gave a TEDx talk (at UNR) titled, "Opposition: The light outside of the dark box," and a UNLV Creates speech entitled, "Consuming to Creating, Watching to Doing, Seeing to Being." To date, she has completed over 55 marathons, seven ultramarathons, three 100 milers, and has a black belt in Taekwondo. 